\title{
A multichannel active system for control of the booming inside a
}

van

\author{
Teresa Bravol, Pedro Cobo ${ }^{l}$ and Juan Manuel Martin ${ }^{2}$ \\ ${ }^{I}$ Instituto de Acústica, CSIC, Serrano 144, 28006 Madrid, Spain \\ ${ }^{2}$ Nissan European Technology Centre-España (NECT-E), Zona Franca, Sector B, C/3, 77 - \\ 111, 08040 Barcelona, Spain
}

\begin{abstract}
Summary: An active sound control (ANC) system has been developed to reduce the booming of a van arisen when the engine noise excites some modes of the passenger compartment. Specially the $80-250 \mathrm{~Hz}$ frequency range is of primary interest. The intention is to implement a feedforward system, using microphones as error sensors and loudspeakers as secondary sources. First, a reference signal, coherent with the unwanted noise, has to be searched. The acoustic field inside the van is expressed as the sum of a series of acoustics modes. The optimal locations of loudspeakers are found by simulated annealing. Finally, the multichannel active noise control system is implemented using a commercial system. Measurements of noise reduction has been carried out in the semianechoic room at NECT-E under usual driving conditions (3rd gear, fast acceleration).
\end{abstract}

\section{INTRODUCTION}

The need for improving comfort levels of vehicle cabins especially involves attention to noise problems. Fuel saving imposes weight limits to the vehicle structure and consequently, inhibits the use of passive tools for noise control. A low frequency periodic noise problem, which is difficult to control using conventional methods, is that due to the engine firing frequency in cars (1).

The aim of this work was to design and implement a practical ANC system for a eight-seats four-cylinder van. For a typical four-cylinder powered vehicle, the most significant contribution to the interior noise is the 2 nd order harmonic of the engine rotational speed. Under usual driving conditions, when the operating engine speed extends from 1500 to 6000 $\mathrm{rpm}$, the 2nd order excitation traverses a frequency range of $50 \mathrm{~Hz}$ to $200 \mathrm{~Hz}$. Internal acoustic modes are excited in this frequency range resulting in increased sound, known as "cabin boom" (2). A 6I/6O ANC system has been designed to control the booming over the whole frequency range under hard driving conditions.

\section{PHYSICAL IMPLEMENTATION OF THE ANC SYSTEM}

In the $6 \mathrm{I} / 6 \mathrm{O}$ ANC configuration, a reference signal feeds into a digital controller, which drives six control signals to minimise the pressure levels at six microphones. Figure 1 shows a schematic view of the ANC control system installed in the van. Once the dominant noise type 
and its frequency range have been identified, a reference signal must be selected maximally coherent with the noise inside the compartment. The spectrum of the reference signal should be dominated by the 2 nd order level. Although these requirements are both satisfied by a tachometer signal (3), the vertical vibration signal picked up by an accelerometer at the left engine mount has been used in this system as reference signal.

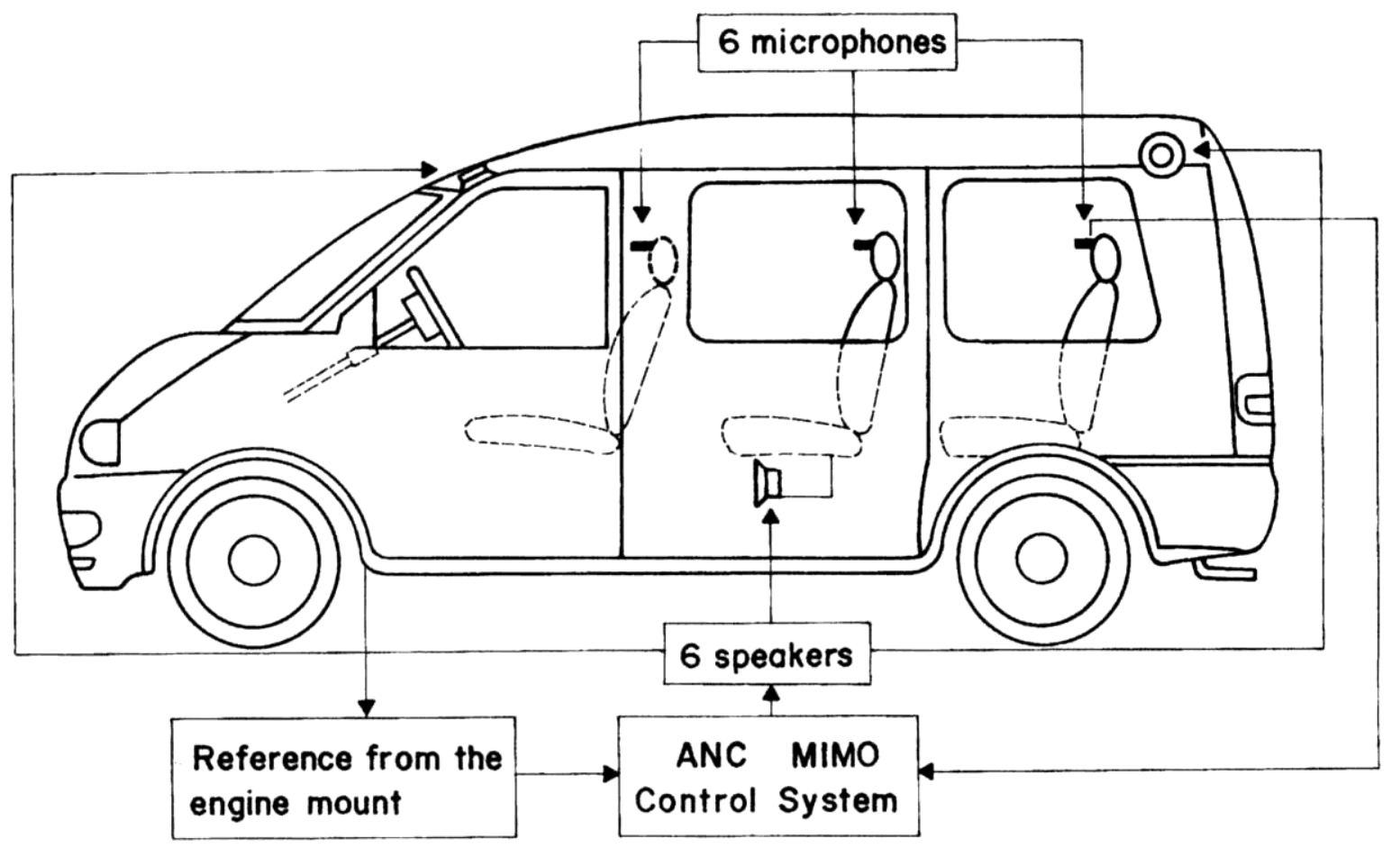

FIGURE 1. Positions of the secondary sources and errors sensors in the prototype van

The positions of the error microphones have been chosen to avoid nodes of the modes arising the booming. Six cheap electret microphones were used, all of them placed on the interior side of the seat headrests (3).

In order to position the six control sources, the acoustic pressure in the cabin at low frequencies can be described as a sum of modal contributions (1). With appropriate placement of the secondary sources it is possible to couple into the interior acoustics modes and reduce the sound levels. Here, the simulated annealing method has been used to find the best six control sources locations from 16, which minimise the sum of the square pressures at microphone positions. If sufficient microphones are used, this sum is proportional to the acoustic potential energy (4). The optimal configuration consisted in four loudspeakers at the upper corners and two under the middle seats (Figure 1).

A fast adaptive filter is required to enable the system to track changes in vehicle speed. A configurable ANC system that implements both the FX-LMS and the FU-LMS algorithms in a 
TI TMS320C40 DSP was used. The secondary paths were identified by using maximum length sequences. Both the system identification and the adaptive filters were FIR in order to reduce the computational effort. It has been observed that the control performance is mainly determined by the control filter rather than by the accuracy of the secondary paths model, so the secondary paths filter lengths have been decreased in favour of the control filter lengths.

\section{EXPERIMENTAL RESULTS}

A wide variety of measurements were done in the prototype vehicle when the ANC system was on. The tests were carried out in the semianechoic room at NECT-E. Figure 2 shows the 2nd order tracking curves at four passenger positions, for a fast run-up of the engine at 3rd gear.
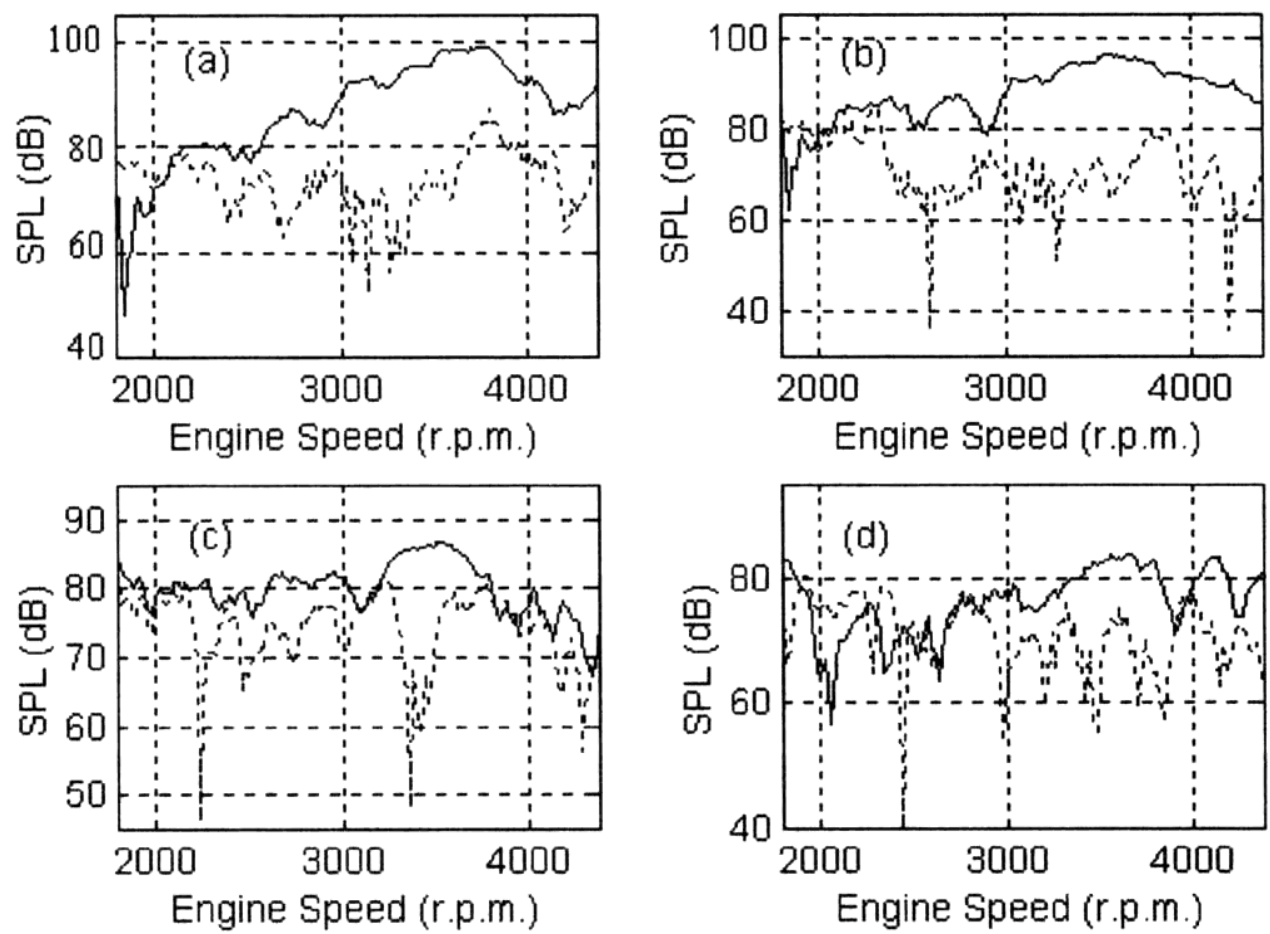

FIGURE 2. 2nd order tracking curves with the ANC system off (solid line) and on (dashed line) for four error microphone positions: (a) driver seat; (b) front right seat; (c) middle right seat ; (d) back right seat

It can be seen that the sound pressure level at $2 \mathrm{nd}$ order was reduced by up to $20 \mathrm{~dB}$ at some frequencies. The others seats are not shown, but the cancellation results are very similar because the symmetrical configuration. This reduction in the 2 nd order harmonic provides an improvement in overall A-weighted sound pressure level. Figure 3 shows this A-weighted sound pressure level at the first error microphone, in the driver position, under the same driving conditions (3rd gear, fast acceleration). 


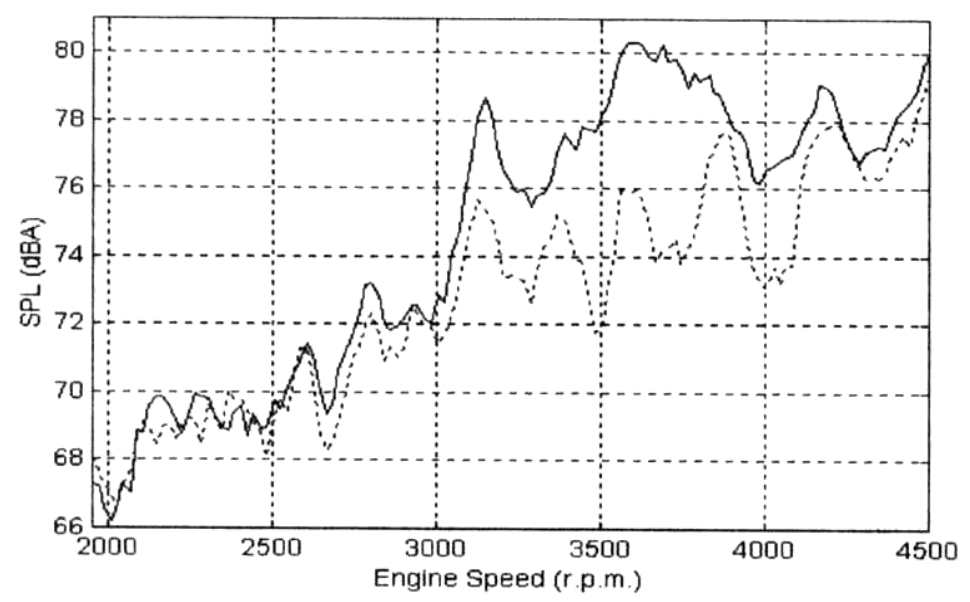

FIGURE 3. Overall A-weighting sound pressure level at the driver position with the ANC system off (solid line) and on (dashed line)

\section{CONCLUSIONS}

A feedforward ANC MIMO system for reduction of the engine boom noise in the passengers compartment has been developed in a van. It is composed of six microphones in the occupant seats, at the head height, and six loudspeakers at the corners and under the middle seats. A commercial system based on a TI TMS320C40 DSP has been used to implement the FX-LMS algorithm. Reductions in the sound pressure level of up to $20 \mathrm{~dB}$ have been obtained for the 2nd engine order while the vehicle was accelerated in third gear. This implies an attenuation in the overall A-weighted sound pressure level of 4-6 dBA, depending on the engine speed and the particular positions in the van.

\section{REFERENCES}

1. Nelson, P.A., Elliott, S.J., Active Control of Sound, London: Academic Press, 1992, ch. 10.

2. Bremigan, C.D., Eriksson, L.J., Eplli, R.J., Stroup, E.S., "Future of Active Sound and Vibration Control in Vehicles", in Proceedings of ACTIVE 95, Newport Beach, CA, USA, pp. 791-802, 1995.

3. Cobo, P., Martín, J.M., "Medidas de ruido y vibraciones en el interior de un vehículo relevantes para el diseño de un sistema CAR multicanal", in Proceedings of ACUSTICA 98, Lisboa, Portugal, pp. 277-280, 1998.

4. Baek, K.H., Elliott, S.J., Journal of Sound and Vibration 186 (2), pp. 245-267 (1995).

\section{ACKNOWLEDGMENTS}

This work has been supported by CICYT, Project AMB97-1175-CO3-01. 